\title{
A Unique Type of Posterior Maxilloethmoidal Cell
}

\author{
Hsing-Won Wang ${ }^{*}, 1,2$, Jiann-Jy Chen ${ }^{3}$, Pin-Zhir Chao ${ }^{2}$ and Fei-Peng Lee Led $^{2,4}$ \\ ${ }^{1}$ Graduate Institute of Clinical Medicine and Department of Otolaryngology, Taipei Medical University-Shuang Ho \\ Hospital, New Taipei, Taiwan \\ ${ }^{2}$ Department of Otolaryngology, School of Medicine, Taipei Medical University, Taipei, Taiwan \\ ${ }^{3}$ Department of Medical Imaging, Taipei Medical University-Shuang Ho Hospital, New Taipei, Taiwan \\ ${ }^{4}$ Department of Otolaryngology, Taipei medical university Wan Fang Hospital, Taipei, Taiwan
}

\begin{abstract}
A 72-year-old female patient presented with a single-sided stuffy nose, headache, purulent running nose and purulent cough for several years. A large posterior maxilloethmoidal cell was noted behind the maxillary sinuses bilaterally and found to drain into the superior nasal meatus. She underwent unilateral functional endoscopic sinus surgery with right ethmoidectomy and middle meatal antrostomy. The postoperative course was uneventful.

A well developed posterior ethmoidal cell extends to superolateral portion of sphenoid sinus is called as Onodi's cell. A well developed posterior ethmoidal cell extends to the maxillary sinus more than $50 \%$ of the antrum space as the case we presented. We have tentatively named this unique finding a posterior "maxilloethmoidal cell."
\end{abstract}

Keywords: Maxilloethmoidal cell, Onodi cell, Haller cell, rhinosinusitis.

\section{INTRODUCTION}

There is variation among otolaryngologists with respect to the radiological definition of paranasal regional anatomy. An accurate evaluation of paranasal anatomic variations is important for endoscopic surgery of the chronic rhinosinusitis [1]. Many anatomical variations of the structures in the middle meatus can lead to stenotic clefts, which can increase contact between mucosal surfaces. This may impede or block ventilation and drainage of the ethmoid sinus (as well as the other large sinuses in proximity). After identification of anatomical variations, functional endoscopic sinus surgery can provide dramatic relief of chronic sinusitis symptoms. High resolution computed tomography (CT) is an effective modality for the preoperative assessment. By using axial plane $\mathrm{CT}$ images, anatomical study of the ethmoidal air cell system can be reliably evaluated. In addition, 3dimensional CT imaging (axial, coronal, and sagittal planes) can display detail of the anatomical variations of the ostiomeatal unit and paranasal sinuses (areas that have been reported to be involved in the pathophysiology of sinusitis). There is close agreement between data obtained from CT scans and those provided by anatomical dissection [2]. We would like to present a unique type of posterior maxilloethmoidal cell that has not been described in the medical literature to date.

*Address correspondence to this author at the Graduate Institute of Clinical Medicine and Department of Otolaryngology, Taipei Medical UniversityShuang Ho Hospital, No. 291, Zhongzheng Road, Zhonghe District, New Taipei City 23561, Taiwan; Tel: +886-2-22490088-2903; Fax: +886-266007866; E-mail: w0512n@ms15.hinet.net

\section{CASE PRESENTATION}

A 72-year-old female patient presented with a single-sided stuffy nose, headache, purulent nasal drainage, and a purulent cough, present for several years. All attempts at managing her with medications had failed to cure her of her symptoms. She visited our clinic where physical examination showed mucopus at right middle nasal meatus. Non-contrast computed tomography of nasal sinus demonstrated right maxillary sinus, ethmoid bulla and maxillary sinus infundibulum were full of soft tissue density. The total Lund-Mackay scoring was 6 (Fig. 1A). In addition, a maxilloethmoidal cell was noted bilaterally and posterior to the maxillary sinuses. The maxilloethmoidal cell drained into the superior nasal meatus (Fig. 1B, C). Right chronic rhinosinusitis and bilateral unique type of maxilloethmoidal cells were diagnosed. Then, ipsilateral functional endoscopic sinus surgery with right ethmoidectomy and right middle meatal antrostomy was recommended. The postoperative course was uneventful.

\section{DISCUSSION}

Cross-sectional computed tomographic imaging has dramatically changed our approach and understanding of the anatomy and pathology of nasal sinuses [1]. Recognition of the nasal anatomic variations is beneficial for identification of the operative limits. The highest degree of variability is found in septal deviation (36\%); followed by the middle nasal concha bullosa $(30 \%)$, sphenomaxillary plate $(17 \%)$, Onodi's cells (sphenoethmoidal cells) (12\%), carotid artery bulging into the sphenoid sinus $(8 \%)$, supraorbital recess (6\%), Haller's cells (6\%), anterior clinoid process pneumatization $(6 \%)$, paradoxical middle turbinate $(3 \%)$, and uncinate process pneumatization (2\%) [2]. The clinical significance of these variations is still under debate. 


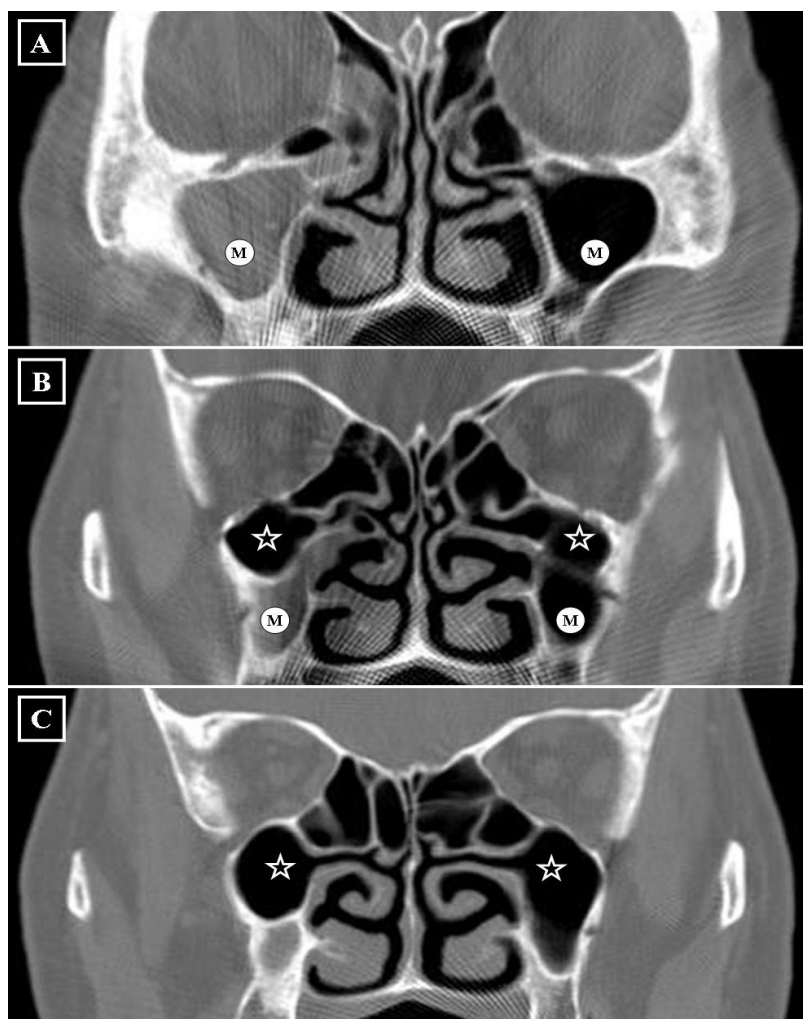

Fig. (1). The coronal sectional series (centre $350 \mathrm{HU}$, width 2,000 HU) of nasal sinuses demonstrated right maxillary sinus (M), right anterior ethmoid bulla and right maxillary sinus infundibulum are full of soft tissue density, diagnosed as rhinosinusitis. The maxillary sinuses (M) are drained into the middle nasal meatus (A). The huge posterior maxilloethmoidal cells (asterisks) locate postero-superior to the both maxillary sinuses (B), like posterior maxillary sinuses, are drained into the superior nasal meatus $(\mathbf{C})$.

The Haller's cell [3] cannot be diagnosed by either physical examination or endoscopy and is found in 6-16.0\% of computed tomographic data [1, 2]. It has yet been defined as (1) an infraorbital cell of the anterior or posterior ethmoid, regardless of its origin [4], or (2) an infraorbital cell of the anterior ethmoid cell, following out the maxillary bone and originating from the ethmoid labyrinth [5]. It may vary in size from relatively small to quite large, extrinsic to the ostiomeatal complex, and should be differentiated from the infraorbital recess of the maxillary sinus [3]. The findings that we have presented in this case do not meet the definitions of a Haller's cell.

For the purpose of pre-operative evaluation, this patient underwent a computed tomographic examination, which demonstrated a large, posterior, maxilloethmoidal cell, overlapping into the right and left maxillary sinuses. A unique type of pathology (distinct from what has been described in the medical literature) was confirmed. We have named the finding a "maxilloethmoidal" cell. Although a common type of Haller's cell is often closely related to infundibulum and narrow down the infundibulum or ostium of maxillary sinus even during a minor inflammation [3], the unique maxilloethmoidal cell in this patient was independent from the maxillary sinus and was not thought to contribute to the right rhinosinusitis. The unique cell should be spared from the functional endoscopic sinus surgery. In a previous study, a similar type of variation was termed an "ethmomaxillary" sinus. This ethmomaxillary sinus was described as an enlarged, posterior, ethmoidal air cell occupying the superior portion of the maxillary sinus. Our case findings differed from this definition of an ethmomaxillary sinus. In our definition of maxilloethmoidal cells, the posterior ethmoidal cell occupied both superior and posterior portions of the maxillary sinus and not draining into the maxillary sinus [6].

A well developed posterior ethmoidal cell extends to superolateral portion of sphenoid sinus is called as Onodi's cell $[7,8]$. This well developed posterior ethmoidal cell extends to the maxillary sinus more than $50 \%$ of the antrum space is tentatively named maxilloethmoidal cell. From a series of highresolution computed tomography analyses of the prevalence of maxilloethmoidal cells, the incidence is approximately $2.5 \%$ (unpublished data). Is the incidence of maxilloethmoidal cells related to maxillary sinusitis? Further studies may be helpful in clarifying this relationship.

\section{CONFLICT OF INTEREST}

The authors confirm that this article content has no conflict of interest.

\section{ACKNOWLEDGEMENTS}

Declared none.

\section{REFERENCES}

[1] Leunig A, Betz CS, Sommer B, Sommer F. Anatomic variations of the sinuses; multiplanar CT-analysis in 641 patients. Laryngorhinootologie 2008; 87: 482-9.

[2] Arslan H, Aydinlioğlu A, Bozkurt M, Egeli E. Anatomic variations of the paranasal sinuses: CT examination for endoscopic sinus surgery. Auris Nasus Larynx 1999; 26: 39-48.

[3] Wanamaker HH. Role of Haller's cell in headache and sinus disease: a case report. Otolaryngol Head Neck Surg 1996; 114: 324-7.

[4] Stammberger HR, Kennedy DW. Paranasal sinuses: anatomic terminology and nomenclature. The Anatomic Terminology Group. Ann Otol Rhinol Laryngol Suppl 1995; 167: 7-16.

[5] Caversaccio M, Boschung U, Mudry A. Historical review of Haller's cells. Ann Anat 2011; 193: 185-90.

[6] Sirikçi A, Bayazit YA, Bayram M, Kanlikama M. Ethmomaxillary sinus: a particular anatomic variation of the paranasal sinuses. Eur Radiol 2004; 14(2): 281-5.

[7] Tomovic S, Esmaeili A, Chan NJ, et al. High-resolution computed tomography analysis of the prevalence of Onodi cells. Laryngoscope 2012; 122: 1470-3.

[8] Meloni F, Mini R, Rovasio S, Stomeo F, Teatini GP. Anatomic variations of surgical importance in ethmoid labyrinth and sphenoid sinus. A study of radiological anatomy. Surg Radiol Anat 1992; 14: 6570 . 